\title{
Article \\ Characterization of Nickel Oxide Nanoparticles Synthesized under Low Temperature
}

\author{
Sung-Jei Hong ${ }^{1, *}$, Hyuk-Jun Mun ${ }^{1}$, Byeong-Jun Kim ${ }^{2}$ and Young-Sung Kim ${ }^{2, *}$ \\ 1 Korea Electronics Technology Institute, Seongnam 13509, Korea; hengel20@naver.com \\ 2 Nano IT Convergence Engineering, Graduate School of NIDE Fusing Technology, Seoul National University \\ of Science \& Technology, Seoul 01811, Korea; kbj1020@seoultech.ac.kr \\ * Correspondence: hongsj@keti.re.kr (S.-J.H.); youngsk@seoultech.ac.kr (Y.-S.K.)
}

check for updates

Citation: Hong, S.-J.; Mun, H.-J.; Kim, B.-J.; Kim, Y.-S. Characterization of Nickel Oxide Nanoparticles Synthesized under Low Temperature. Micromachines 2021, 12, 1168. https:/ / doi.org/10.3390/mi12101168

Academic Editors: Dae-Joon Kang, Moongyu Jang, Won-Seok Chang, Junhong Min, Wan-Soo Yun and Jong-Ryul Jeong

Received: 4 September 2021

Accepted: 22 September 2021

Published: 28 September 2021

Publisher's Note: MDPI stays neutral with regard to jurisdictional claims in published maps and institutional affiliations.

Copyright: (c) 2021 by the authors. Licensee MDPI, Basel, Switzerland. This article is an open access article distributed under the terms and conditions of the Creative Commons Attribution (CC BY) license (https:// creativecommons.org/licenses/by/ $4.0 /)$.

\begin{abstract}
In this study, ultrafine nickel oxide nanoparticles (NiO NPs) were well synthesized using a simple wet chemical method under low temperature, $300{ }^{\circ} \mathrm{C}$. An $\mathrm{Ni}(\mathrm{OH})_{2}$ precursor was well precipitated by dropping $\mathrm{NH}_{4} \mathrm{OH}$ into an $\mathrm{Ni}(\mathrm{Ac})_{2}$ solution. TG-DTA showed that the weight of the precipitate decreases until $300{ }^{\circ} \mathrm{C}$; therefore, the precursor was heat-treated at $300{ }^{\circ} \mathrm{C}$. X-ray diffraction (XRD) patterns indicated that hexagonal-structured NiO NPs with (200) preferred orientation was synthesized. In addition, BET specific surface area (SSA) and HRTEM analyses revealed that spherical NiO NPs were formed with SSA and particle size of $60.14 \mathrm{~m}^{2} / \mathrm{g}$ and ca. 5-15 $\mathrm{nm}$ by using the low temperature method. FT-IR spectra of the NiO NPs showed only a sharp vibrating absorption peak at around $550 \mathrm{~cm}^{-1}$ owing to the Ni-O bond. Additionally, in UV-vis absorption spectra, the wavelength for absorption edge and energy band gap of the ultrafine NiO NPs was $290 \mathrm{~nm}$ and $3.44 \mathrm{eV}$.
\end{abstract}

Keywords: nickel oxide nanoparticles (NiO NPs); wet chemical synthesis; heat-treatment under low temperature; hexagonal structure; FT-IR spectra; Ni-O bond; UV-Vis spectra; blue shift; quantum confinement effect

\section{Introduction}

Nickel oxide $(\mathrm{NiO})$ is an important transition metal oxide material with a cubic lattice structure used in numerous applications [1,2]. NiO nanoparticles (NPs) have a wide range of applications such as battery electrodes, photo-electron devices, ion storage materials, gas sensors, magnetic materials, thermoelectric materials, catalysts, fuel cells, dye-sensitized photocathodes, electrochromic films, anticancer properties, cytotoxic activity and nonenzymatic glucose sensors, etc. [3,4]. In addition, $\mathrm{NiO}$ nanoparticles (NPs) are studied because nano-dimensional particles differ from the majority of nanoparticles in a number of properties, including surface area to volume ratio and electro-optical, magneto-optical, chemical and mechanical properties, which lead to unique optical, electronic and physiochemical properties [5]. With advancements in all areas of industry and technology, interest has been focused on nanoscale materials, stemming from the fact that new properties are required at this length scale and, equally important, that these properties change with their size and morphology [6]. Size reduction affects most physical properties (structural, magnetic, optical, dielectric, thermal, etc.) due to surface effects and quantum size effects [7].

Several methods have been attempted to prepare NiO NPs [8-12], but many come with disadvantages because the process is complicated and consumes large amounts of energy to induce a large amount of carbon. Although some methods have been reported as synthesizing them while decreasing consumption energy [8], there are still issues, including the limitation of manufacturing capacity for use in production lines, etc. Accordingly, simple and cost-effective synthetic methods are important in order to reach global carbon neutrality.

In this study, we synthesized NiO NPs by using an eco-friendly method under a low temperature that uses less energy. Although we selected a simple wet chemical method that 
is generally used in a production line, we synthesized NiO NPs by using acetate-based raw materials that do not contain harmful substances such as $\mathrm{Cl}^{-}$or $\mathrm{NO}_{3}{ }^{-}$, resulting in a decrease of wastewater. Existing synthetic methods using materials containing harmful substances require several washing steps with water to remove those substances, and a significant amount of wastewater is generated during the repeated cleaning steps, whereas the acetate substance is easily washed into water, with the result that the number of washing steps and the amount of wastewater generation can be decreased by applying acetate-based raw materials. In addition, we attempted to lower the heat-treatment temperature to optimize ultrafine-sized NiO NPs as well as to reduce carbon emission.

\section{Materials and Methods}

\subsection{Preparation of $\mathrm{NiO} N \mathrm{NS}$}

Nickel (II) acetate tetrahydrate $\left(\mathrm{Ni}\left(\mathrm{CH}_{3} \mathrm{CO}_{2}\right)_{2} \cdot 4 \mathrm{H}_{2} \mathrm{O}\right)$ was used as a raw material. Salt was dissolved into ethanol, and $2.0 \mathrm{M}$ ammonia $\left(\mathrm{NH}_{4} \mathrm{OH}\right)$ was added dropwise into the solution to precipitate a precursor of NiO NPs. The precipitate was then centrifugated and dried at $70^{\circ} \mathrm{C}$. To determine the lowest heat-treatment temperature where components are thermally decomposed, except $\mathrm{Ni}$ to be oxidized, examination of thermal behavior of the precipitate was conducted using thermogravimetric analysis (TGA) and differential thermal analysis (DTA) at temperatures ranging from $25^{\circ} \mathrm{C}$ to $550{ }^{\circ} \mathrm{C}$ with a rising rate of $10{ }^{\circ} \mathrm{C} / \mathrm{min}$. Based on the result, heat-treatment temperature was determined from the thermally decomposed point, $300^{\circ} \mathrm{C}$, to $600{ }^{\circ} \mathrm{C}$ at an increment of $100{ }^{\circ} \mathrm{C}$, and four $\mathrm{NiO}$ NPs samples were prepared.

\subsection{Characterizations of $\mathrm{NiO} N \mathrm{NS}$}

The prepared NiO NPs samples were characterized as follows: crystal structures were analyzed by using an X-ray diffractometer (XRD, Empyrean, Malvern Panalytical B.V., Almelo, Netherlands) with $\mathrm{Cu} K$ radiation over a range of $2 \theta$ angles from $20^{\circ}$ to $80^{\circ}$. In addition, XRD pattern of the precipitate before heat-treatment was analyzed to determine its compound forms. Their surface areas were measured with a Brunauer, Emmett \& Teller surface area analyzer (BET SSA, ASAP2020, Micromeritics, Norcross, GA, USA). Their particle size and morphology were observed using a high-resolution transmission electron microscope (HRTEM, JEM-2010, JEOL, Tokyo, Japan). Their chemical structures were examined using Fourier transform infrared spectroscopy (FT-IR, IRAffinity-1S, Shimadzu, Kyoto, Japan) in the range of $400-4000 \mathrm{~cm}^{-1}$. In addition, their UV-Vis absorption spectra were investigated at room temperature by using a UV-Vis spectrophotometer (CM-3600d, Konica Minolta, Tokyo, Japan) in the range of 300-800 nm.

\section{Results}

\subsection{Crystal Structure}

Firstly, we analyzed the crystal structure of the precipitate from the Ni (II) acetate reacted with ammonia solution. Its XRD pattern is shown in Figure 1. Most peaks are indexed to those of a pure phase of $\mathrm{Ni}(\mathrm{OH})_{2}$ with a hexagonal structure [13], i.e., it appears to be reduced and precipitated in the form of $\mathrm{Ni}(\mathrm{OH})_{2}$ as follows:

$$
\mathrm{Ni}\left(\mathrm{CH}_{3} \mathrm{CO}_{2}\right)_{2}+2 \mathrm{NH}_{4} \mathrm{OH} \rightarrow \mathrm{Ni}(\mathrm{OH})_{2}+2 \mathrm{NH}_{4}\left(\mathrm{CH}_{3} \mathrm{CO}_{2}\right)
$$

Next, we analyzed the thermal behavior of the $\mathrm{Ni}(\mathrm{OH})_{2}$ precipitate. In Figure 2, the thermal weight of the precipitate (red color) tends to decrease as the temperature increases, and the weight rapidly decreases from $250{ }^{\circ} \mathrm{C}$ to $300{ }^{\circ} \mathrm{C}$, maintaining a constant of about $55 \%$ weight above $300^{\circ} \mathrm{C}$. In addition, from the DTA graph of the $\mathrm{Ni}(\mathrm{OH})_{2}$ precipitate (blue color), an exothermic behavior was observed in the range of $250{ }^{\circ} \mathrm{C}$ to $300{ }^{\circ} \mathrm{C}$. The decrease in weight is due to the decomposition and evaporation of $\mathrm{H}$ and $\mathrm{O}$ components, excepting the Ni component, which were included in the $\mathrm{Ni}(\mathrm{OH})_{2}$ precipitate. Therefore, it appears possible to prepare crystalline $\mathrm{NiO} N$ Ps by a heat-treatment of above $300^{\circ} \mathrm{C}$. 


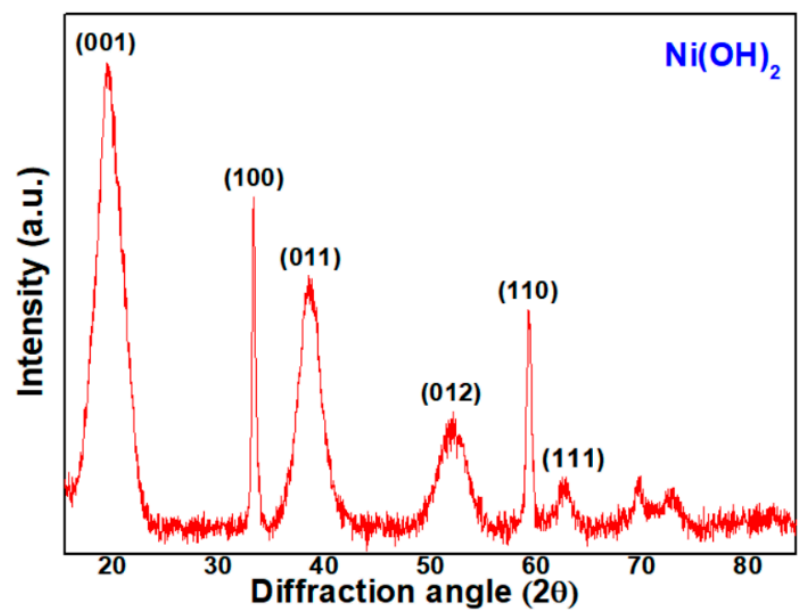

Figure 1. XRD pattern of the precipitate from $\mathrm{Ni}(\mathrm{II})$ acetate with ammonia.

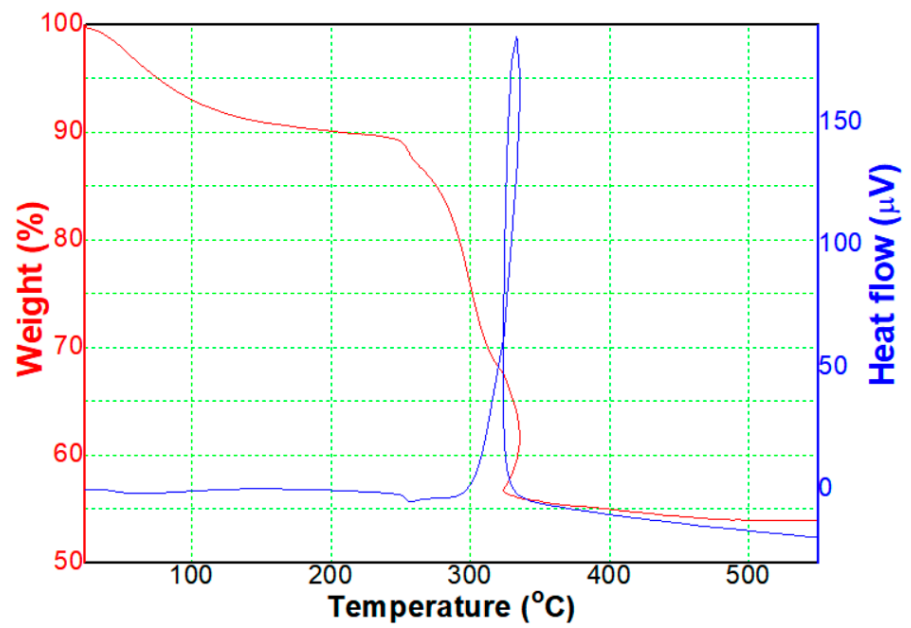

Figure 2. Thermal behavior of the precipitate.

The XRD patterns of the four NiO NPs samples are presented in Figure 3a-d. Despite the differences in heat-treatment temperature of each sample, all samples show a similar diffraction pattern. The NiO NPs heat-treated at $300{ }^{\circ} \mathrm{C}$ in Figure 3 a have main diffraction peaks at $37.23^{\circ}, 43.32^{\circ}, 62.80^{\circ}, 75.47^{\circ}$ and $79.47^{\circ}$, indicating $\left.\left.<111>,<200\right\rangle,<220\right\rangle,<311>$ and $<222>$ directions, respectively. Among them, the growth was greatest in the $<200>$ direction, indicating a hexagonal structure with the $<200>$ preferred orientation. Additionally, in Figure $3 \mathrm{~b}-\mathrm{d}$, the samples heat-treated at $400{ }^{\circ} \mathrm{C}, 500{ }^{\circ} \mathrm{C}$, and $600{ }^{\circ} \mathrm{C}$ showed diffraction patterns similar to those of $300{ }^{\circ} \mathrm{C}$. Thus, it is evident that all the NiO NPs samples have the same hexagonal structure. 


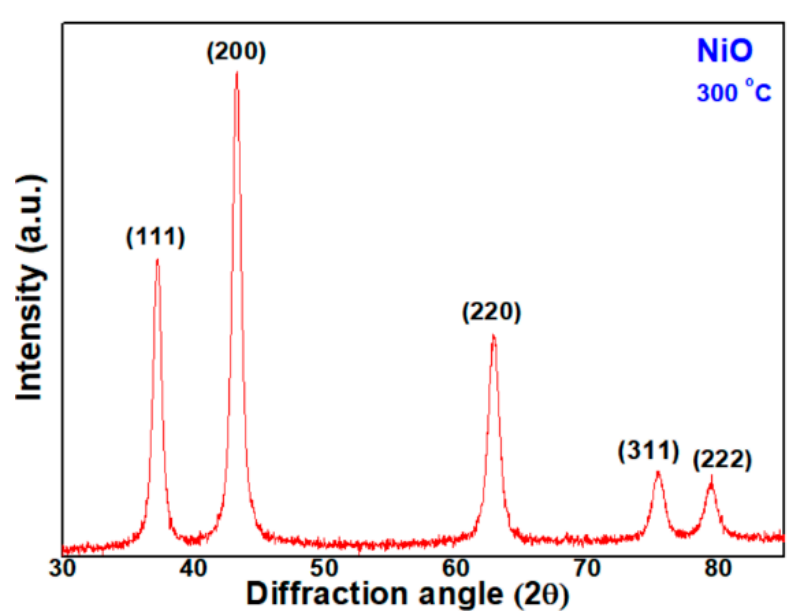

(a)

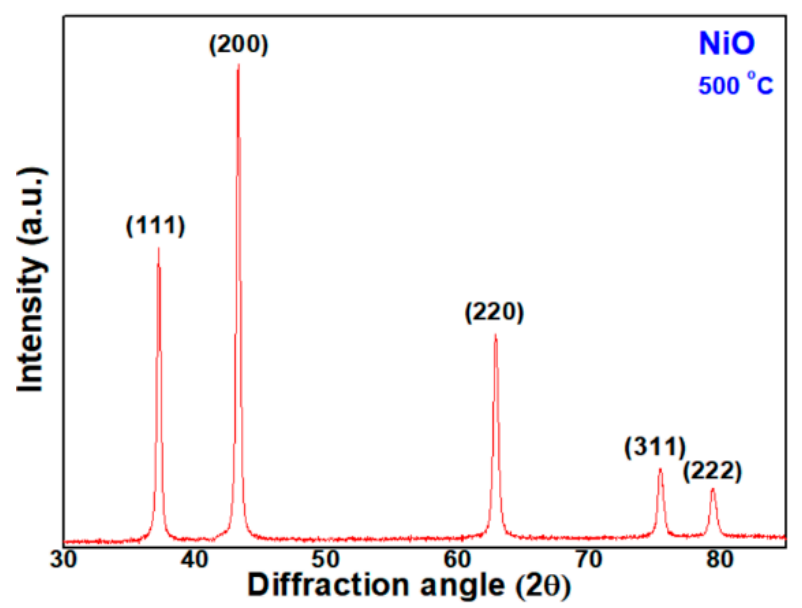

(c)

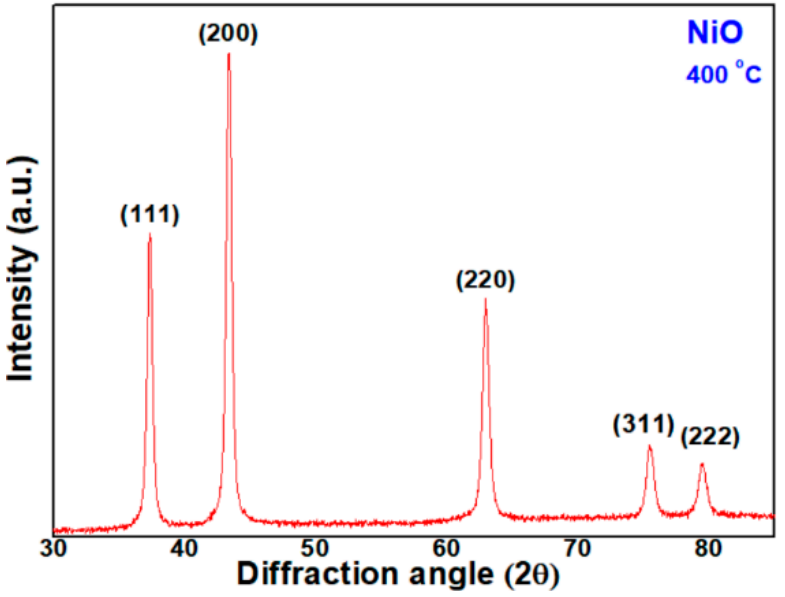

(b)

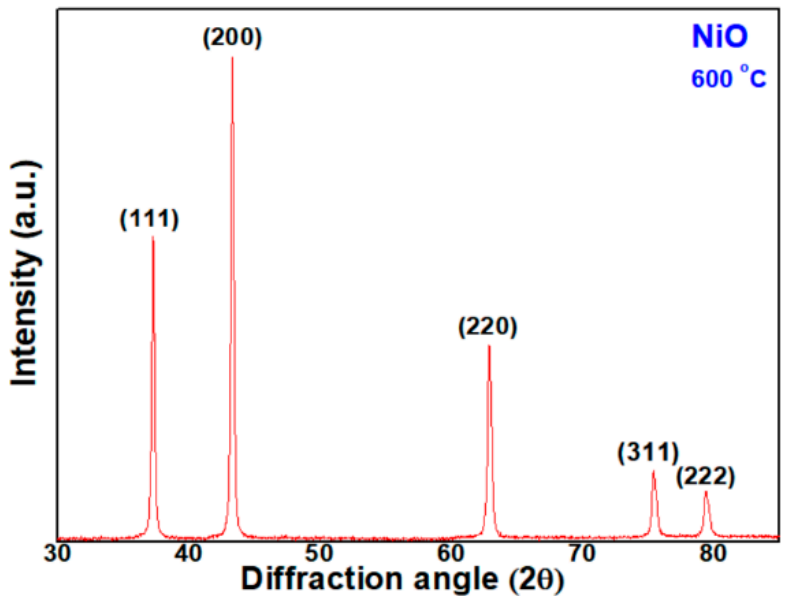

(d)

Figure 3. XRD patterns of $\mathrm{NiO} N P s$ heat-treated at (a) $300{ }^{\circ} \mathrm{C}$; (b) $400{ }^{\circ} \mathrm{C}$; (c) $500{ }^{\circ} \mathrm{C}$; (d) $600{ }^{\circ} \mathrm{C}$.

\subsection{Particle Size}

From the XRD peaks, the full-width-half-maximum (FWHM) of the $<200>$ peak decreased as the heat-treatment temperature increased. This result indicates that the size of the NiO NPs heat-treated at lower temperatures is ultrafine nanocrystal according to the Scherrer's Equation [14]. From the XRD peaks, particle size can be calculated by using Scherrer's Equation as

$$
\mathrm{t}=0.9 \lambda / \mathrm{B} \cos \theta_{\mathrm{B}}
$$

where $t, \lambda, B$ and $\theta_{B}$ are particle size, wavelength (0.1542 $\mathrm{nm}$ for $\mathrm{CuK}_{\alpha}$ radiation), fullwidth-half-maximum (FWHM) of a peak in radians and diffracted angle, respectively. In Equation (2), the peak intensity increases along with a reduction in the peak half width, indicating the growth of NiO NPs. Thus, as the FWHM is widened, the particle size is reduced. In Figure 4, calculated with Equation (2), particle size of NiO NPs heat-treated at $300{ }^{\circ} \mathrm{C}, 400{ }^{\circ} \mathrm{C}, 500{ }^{\circ} \mathrm{C}$ and $600{ }^{\circ} \mathrm{C}$ was $10.1 \mathrm{~nm}, 17.0 \mathrm{~nm}, 24.6 \mathrm{~nm}$ and $33.6 \mathrm{~nm}$, respectively. Particle size increased in a linear proportion to the heat-treatment temperature.

BET SSA of the samples were measured in the next stage; the results are shown in Figure 5. The SSA of the NiO NPs heat-treated at $300^{\circ} \mathrm{C}$ is above $60.14 \mathrm{~m}^{2} / \mathrm{g}$. Furthermore, in the cases of samples heat-treated at higher temperatures of $400{ }^{\circ} \mathrm{C}, 500{ }^{\circ} \mathrm{C}$ and $600{ }^{\circ} \mathrm{C}$, SSA decreased to $27.19 \mathrm{~m}^{2} / \mathrm{g}, 15.67 \mathrm{~m}^{2} / \mathrm{g}$ and $9.94 \mathrm{~m}^{2} / \mathrm{g}$, respectively. The SSA heat-treated at $600{ }^{\circ} \mathrm{C}$ decreased to roughly one sixth of that heat-treated at $300{ }^{\circ} \mathrm{C}$. 


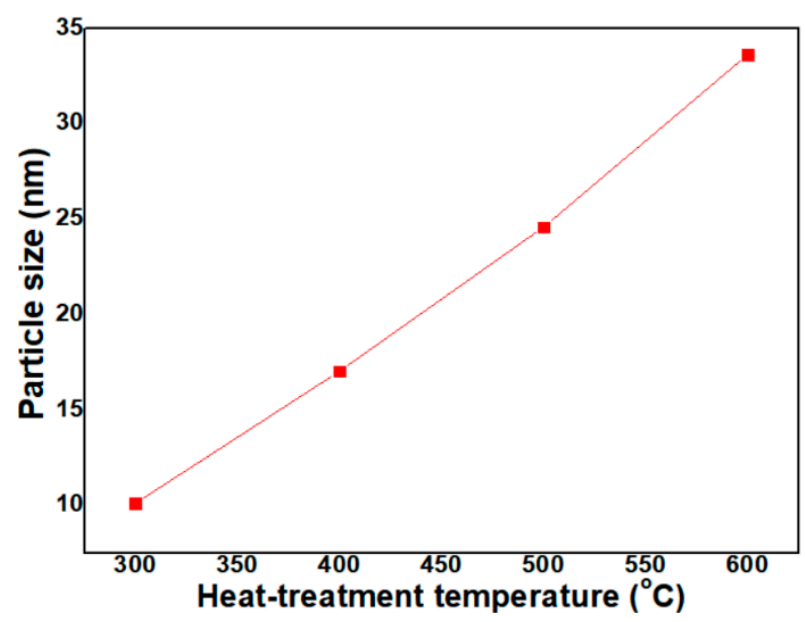

Figure 4. Variation of particle size of NiO NPs with heat-treatment temperature (calculated by using Equation (2)).

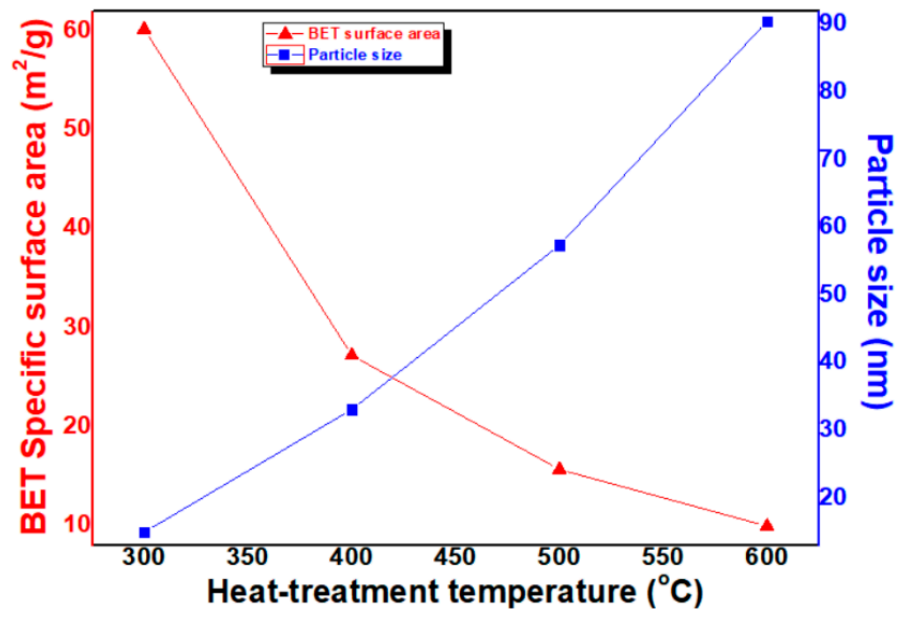

Figure 5. Variation of BET SSA and particle size (calculated by using Equation (3)) of NiO NPs with heat-treatment temperature.

Particle size was calculated from the BET SSA as follows (see Equation (3)):

$$
D=6 / \varrho \cdot d
$$

where D, $\varrho$ and $d$ are particle size, SSA and density, respectively. In Figure 5, the calculated particle size of NiO-NPs heat-treated at $300^{\circ} \mathrm{C}, 400{ }^{\circ} \mathrm{C}, 500{ }^{\circ} \mathrm{C}$ and $600^{\circ} \mathrm{C}$ was $15.0 \mathrm{~nm}, 33.1$ $\mathrm{nm}, 57.4 \mathrm{~nm}$ and $90.5 \mathrm{~nm}$, respectively. The SSA tends to decrease in inverse proportion to the heat-treatment temperature. In addition, in the conversion to particle size, the particle size increases in proportion to the heat-treatment temperature. It was found that there is a difference in the conversion of particle size values between XRD FWHM and BET SSA. It has been reported previously [15] that these differences are owing to measurement principles. In case of XRD FWHM, an X-ray can penetrate through the crystal size to provide information; therefore, the calculation of size is not related to the particles but to the crystals. In addition, it is hard to provide separation and distinguish between broadening through the crystallite size and broadening due to other parameters and factors, whereas in the case of BET SSA, under normal atmospheric pressure and at the boiling temperature of liquid nitrogen, the amount of nitrogen absorbed in relation to pressure gives the SSA of the nanoparticles. Errors may always occur, but successful calculation methods are those that decrease the errors in the best possible way to yield more accurate 
data. Although there is such a difference here, the results show that the increase in particle size due to the increase in heat-treatment temperature is consistent.

Thus, to certify the particle sizes of NiO NPs heat-treated at these temperatures, the samples were observed with HRTEM. In the case of NiO NPs heat-treated at $300^{\circ} \mathrm{C}$, shown in Figure 6a, ultrafine spherical particles with particle sizes of ca. $5 \sim 15 \mathrm{~nm}$ were observed. When the heat-treatment temperature increased to $400{ }^{\circ} \mathrm{C}$, shown in Figure $6 \mathrm{~b}, \mathrm{NiO}$ NPs grew to ca. $20 \sim 40 \mathrm{~nm}$, and particles were slightly agglomerated. The agglomerations between particles became more evident as heat-treatment temperature increased. In the case of $\mathrm{NiO}$ NPs heat-treated at $500{ }^{\circ} \mathrm{C}$, shown in Figure $6 c$, particles of ca. $30 \sim 70 \mathrm{~nm}$ were observed. Additionally, particles of ca. $40 \sim 120 \mathrm{~nm}$ were observed when the heat-treatment temperature increased to $600{ }^{\circ} \mathrm{C}$, as shown in Figure 6d.

Similar to the particle sizes calculated from XRD FWHM and BET SSA, it was clearly observed that particle size increased as the heat-treatment temperature increased. Also, it became evident that NiO NPs were more agglomerated as the heat-treatment temperature was raised. This result is attributed to the diffusion between particles activating as heat-treatment temperature increases. Details on this behavior are further reported in the discussion chapter.
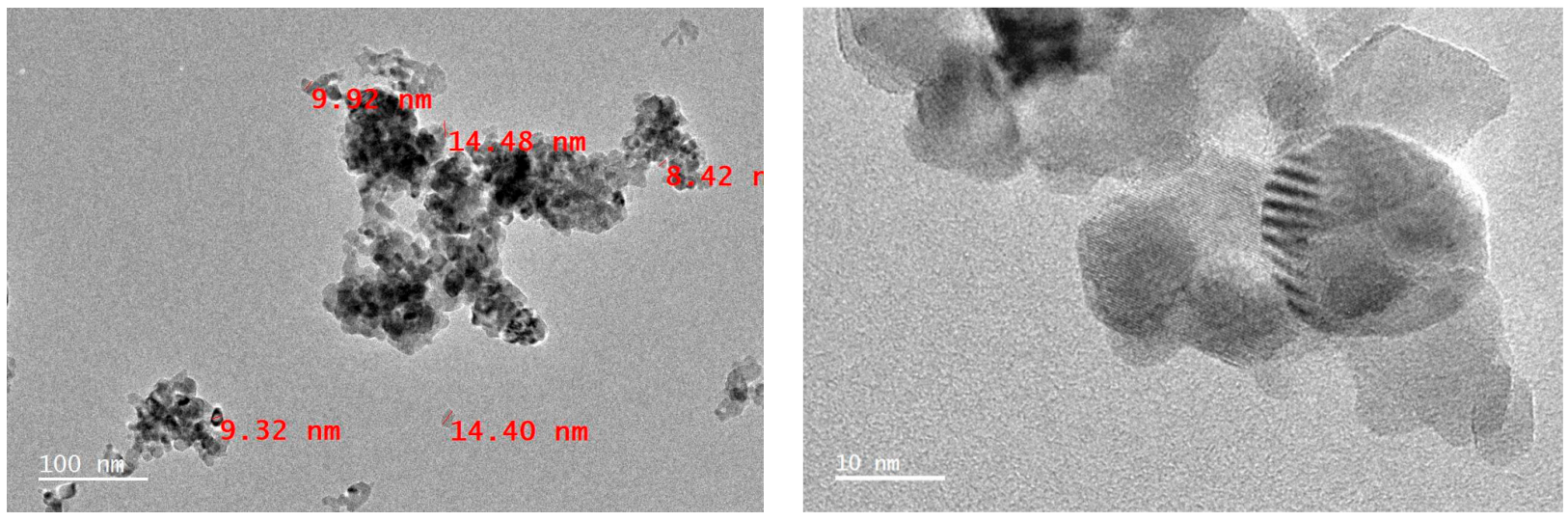

(a)
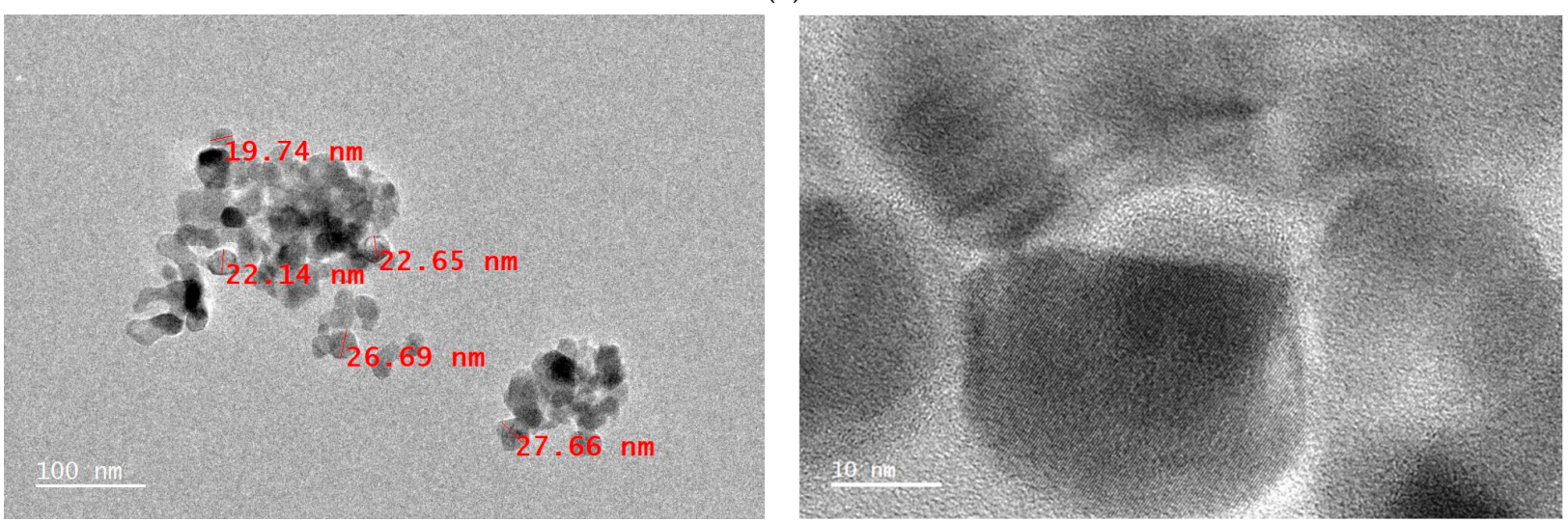

(b)

Figure 6. Cont. 

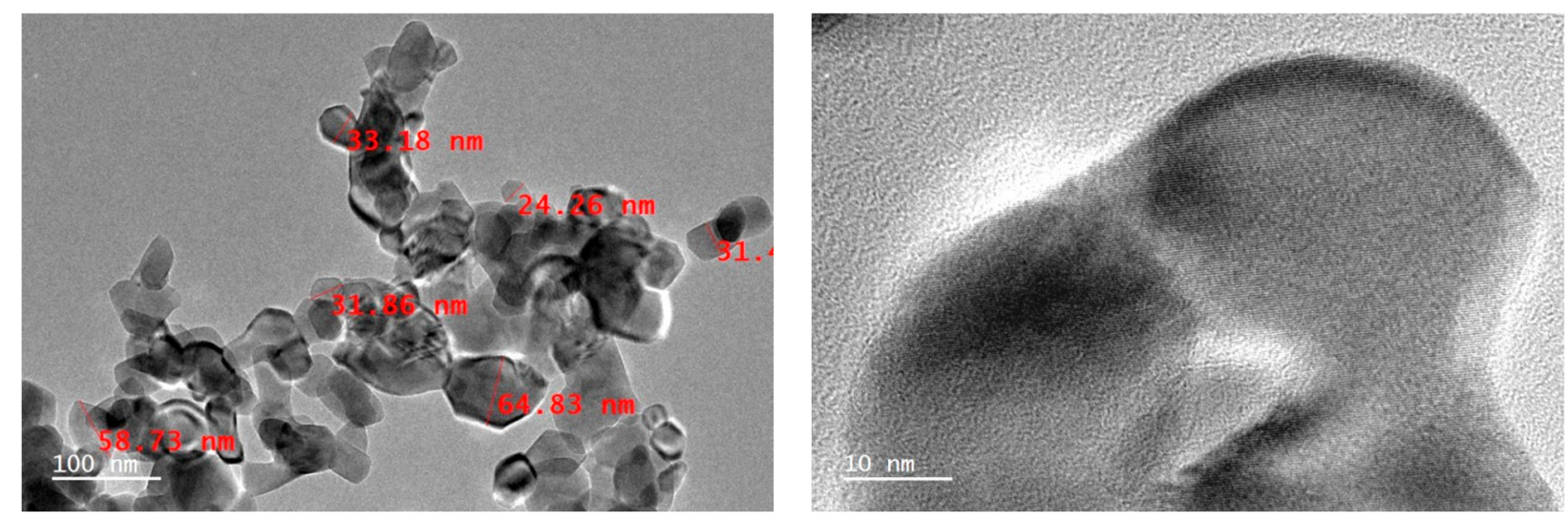

(c)
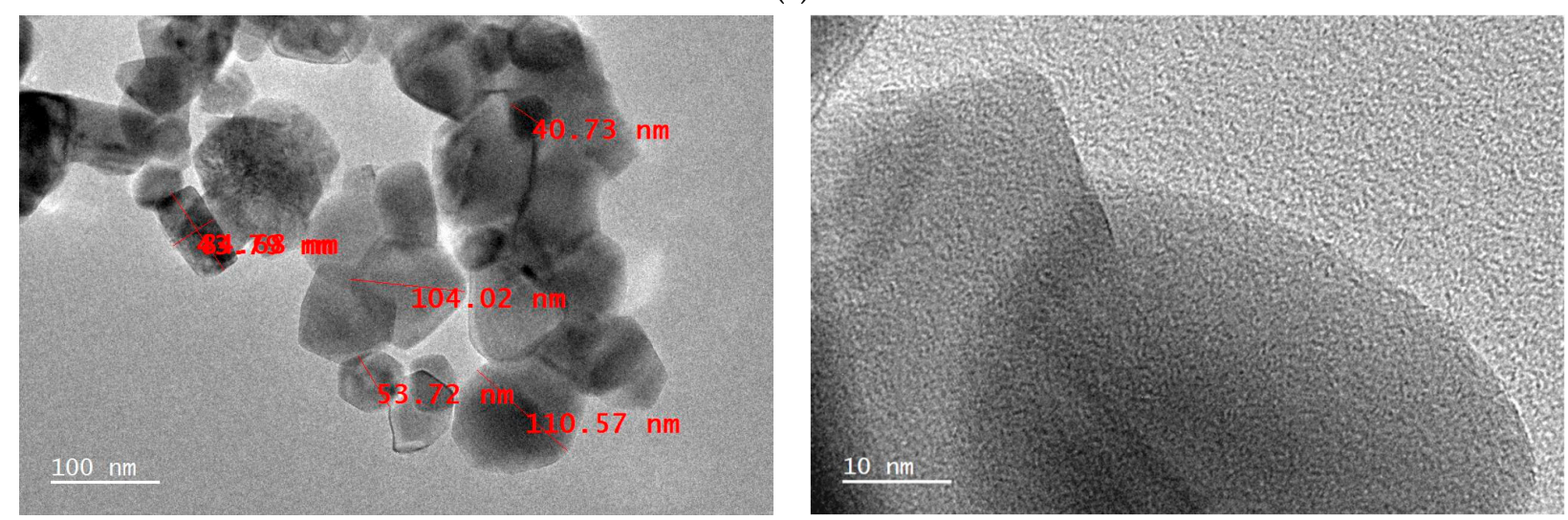

(d)

Figure 6. HRTEM observations of NiO NPs heat-treated at (a) $300^{\circ} \mathrm{C}$; (b) $400{ }^{\circ} \mathrm{C}$; (c) $500{ }^{\circ} \mathrm{C}$; (d) $600{ }^{\circ} \mathrm{C}$.

\subsection{FT-IR Spectra}

To clarify chemical structures of Ni-O bonds in the NiO NPs, the characterization of the molecular structure and nature of chemical bonding in NiO NPs were assessed using FT-IR analysis. In Figure 7, the FT-IR spectra of $\mathrm{NiO} N$ Ps are shown after heat-treatment at $300{ }^{\circ} \mathrm{C}, 400{ }^{\circ} \mathrm{C}, 500{ }^{\circ} \mathrm{C}$ and $600{ }^{\circ} \mathrm{C}$, respectively. All samples showed a similar FT-IR vibration absorption pattern, and a sharp absorption peak was only observed around $550 \mathrm{~cm}^{-1}$ with a wavenumber $(v)$ indicating that it can be attributed to the oscillation of $\mathrm{Ni}-\mathrm{O}$ [16]. The intensity of the absorption peak was also similar in the four samples. From these results, it is inferred that $\mathrm{NiO}$ NPs exhibit a constant vibration absorption peak at a constant wavenumber $(v)$ despite differences in particle size.

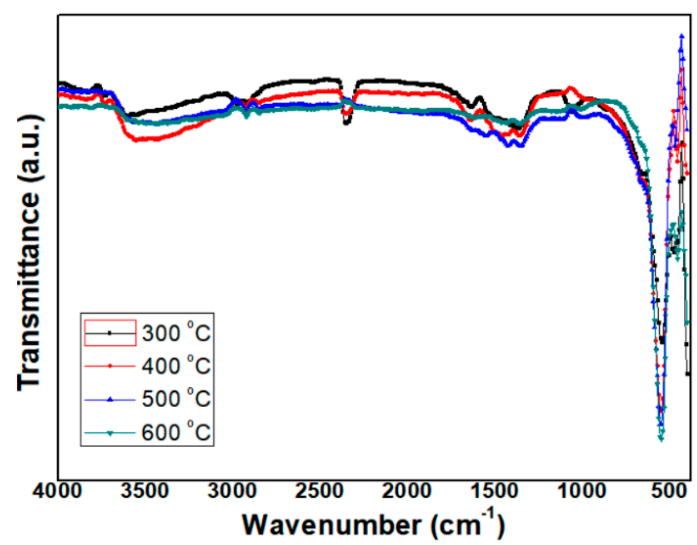

Figure 7. FT-IR spectra of NiO NPs heat-treated at various temperature. 


\subsection{UV-Vis Absorption Spectra}

UV-vis absorption behaviors of $\mathrm{NiO} N P$ samples were analyzed to gather information on its optical band gap. In Figure 8a, the UV-vis spectra of the NiO NPs are shown after heat treatment at $300{ }^{\circ} \mathrm{C}, 400{ }^{\circ} \mathrm{C}, 500{ }^{\circ} \mathrm{C}$ and $600{ }^{\circ} \mathrm{C}$, respectively. The absorption tends to increase towards the shorter wavelength region, showing a phenomenon in which the absorption rate increases in the blue shift, i.e., UV region [17]. In addition, the wavelength for absorption edge of $\mathrm{NiO} N \mathrm{Ns}$ heat-treated at $300{ }^{\circ} \mathrm{C}, 400{ }^{\circ} \mathrm{C}, 500{ }^{\circ} \mathrm{C}$ and $600{ }^{\circ} \mathrm{C}$ is $290 \mathrm{~nm}$, $301 \mathrm{~nm}, 317 \mathrm{~nm}$ and $338 \mathrm{~nm}$, respectively. As the heat-treatment temperature is lowered, the wavelength decreases with it. Moreover, as the heat-treatment temperature is lowered, the absorbance at the absorption edge is raised. This decrease in particle size may be responsible for the shifting of absorption bands towards a lower wavelength [18].

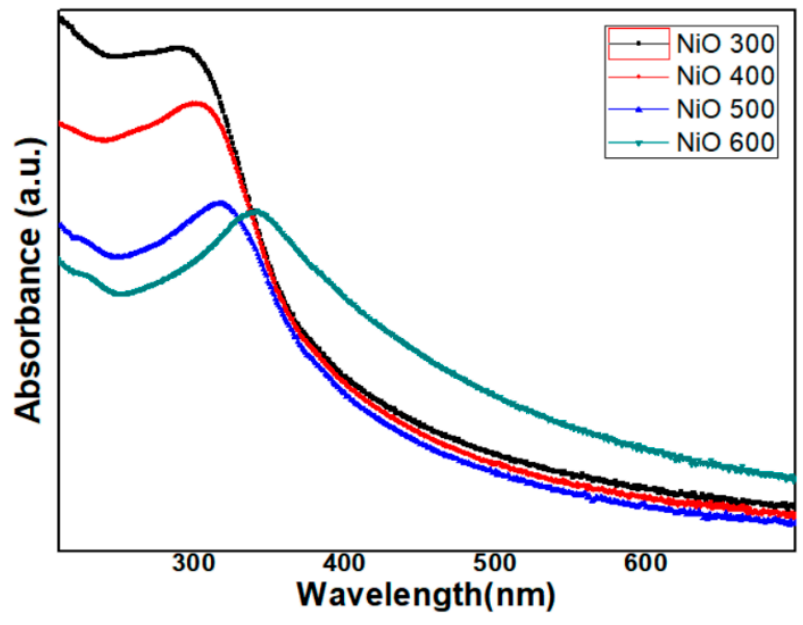

(a)

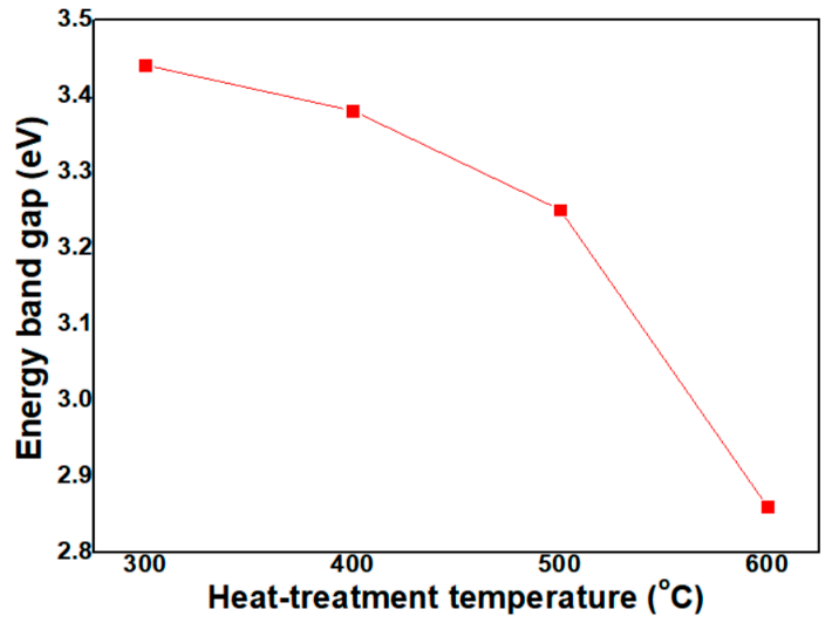

(b)

Figure 8. (a) UV-vis absorption spectra; (b) Energy band gap of NiO NPs heat-treated at $300{ }^{\circ} \mathrm{C}, 400{ }^{\circ} \mathrm{C}, 500{ }^{\circ} \mathrm{C}$ and $600{ }^{\circ} \mathrm{C}$, respectively.

In the next step, the energy band gap of the NiO NPs was calculated by a well-known relation given by Tauc, using Equation (4) [19]:

$$
(\alpha h v)^{1 / n}=A\left(h v-E_{g}\right)
$$

where $\alpha, \mathrm{A}, \mathrm{h}, v, \mathrm{n}\left(=1 / 2\right.$ for direct band gap) and $\mathrm{E}_{\mathrm{g}}$ are optical absorption coefficient, absorbance, Planck's constant, frequency of light, constant related to mode of transition and band gap energy, respectively. Band gap energy was calculated by extrapolating the straight region of the graph plotted between " $\mathrm{h} v$ " and $(\alpha \mathrm{hv})^{2}$. The results show that the band gap energy of NiO NPs heat-treated at $300^{\circ} \mathrm{C}, 400{ }^{\circ} \mathrm{C}, 500{ }^{\circ} \mathrm{C}$ and $600{ }^{\circ} \mathrm{C}$ is $3.44 \mathrm{~V}, 3.38 \mathrm{eV}, 3.25 \mathrm{eV}$ and $2.86 \mathrm{eV}$, respectively, as is shown in Figure $8 \mathrm{~b}$. As the heat-treatment temperature is lowered, the energy band gap is raised. This tendency appears to be related to differences in particle size; details on this tendency are discussed further in the next chapter.

\section{Discussion}

\subsection{Particle Size}

The variation in particle size during heat-treatment temperature change is attributed to particle growth driven by heat-treatment temperature. One mechanism used to increase nanoparticle size is due mainly to particle surface migration [20]. According to transformation kinetics,

$$
\mathrm{D}=\exp (-\mathrm{Q} / \mathrm{kT})
$$

where $\mathrm{D}, \mathrm{Q}, \mathrm{k}$ and $\mathrm{T}$ are mean particle size, activation energy for particle surface migration, Boltzmann constant and heat-treatment temperature, respectively. When the activation 
energy for particle growth becomes small at constant particle size, the surface activity of $\mathrm{NiO}$ NPs as a function of its temperature becomes high, and the growth of nanoparticles can be suppressed as the heat-treatment temperature is lowered. Thus, the lower temperature is necessary to synthesize smaller sized nanoparticles, and $300{ }^{\circ} \mathrm{C}$ is the lowest heat-treatment temperature for the crystalline NiO NPs.

\subsection{FT-IR Spectra}

In FT-IR spectra, the absorption peaks and their positions are attributed to the chemical composition, crystalline nature and morphology of the material, and the absorption peaks below $1000 \mathrm{~cm}^{-1}$ are considered to be essential for studying presence of $\mathrm{Ni}-\mathrm{O}$ bonds in $\mathrm{NiO}$ NPs [17]. In Figure 7, the sharp vibration peaks at around $550 \mathrm{~cm}^{-1}$ in the spectra appear to relate to the Ni-O stretching [16]. In addition, any other vibration absorption patterns which appeared by peaks related to organic bonding, such as $\mathrm{O}-\mathrm{H}, \mathrm{C}-\mathrm{O}, \mathrm{C}-\mathrm{C}, \mathrm{C}=\mathrm{O}$ and $\mathrm{C}=\mathrm{C}$, were scarcely observed, indicating that there is a pure $\mathrm{Ni}-\mathrm{O}$ bond with few organic residues, i.e., the NiO NPs have high purity. Beyond this, it is known that NiO NPs exhibit a constant vibration absorption peak at a constant wavenumber $(v)$ regardless of differences in particle size. This is assumed to be related to the lattice parameter, i.e., from the XRD patterns, it is known that the four NiO NP samples have the same lattice parameter, $0.418 \mathrm{~nm}$. Because of the same bonding length between $\mathrm{Ni}$ and $\mathrm{O}$ of all the samples, it is theorized that they exhibit almost the same vibration absorption peak at a constant wavenumber, however, further study is required to identify the relationship clearly.

\subsection{UV-Vis Absorption Spectra}

UV-visible absorption spectroscopy is an important method for estimating the energy structures and optical properties of nanoparticles. Discussion on the increased trend of band gap energy as it relates to decreases in particle size is well documented in existing literature [21,22]. It is additionally well documented that semiconductors with nanoscale size show a blue shift in their spectra due to quantum confinement effects [21]. The phenomenon of the blue shift occurs with an attendant increase in the band gap value, which is evidence of a quantum confinement effect. This implies that the band gap value became larger with decrease in particle size. Generally, as particle size decreases, the wavelength of the maximum exciton absorption $\left(\lambda_{\max }\right)$ decreases due to the quantum confinement of the photo generated electron-hole carriers [22]. It is noted that NiO NPs exhibit a blue shift in the absorption onset; this blue shift in the absorption spectrum is mainly attributed to the confinement of charge carriers in the NiO NPs. $\alpha$ obeys Equation (4) for high photon energies $(\mathrm{h} v)$, and the fundamental absorption corresponding to the optical transition of the electrons from the valence band to the conduction band can be used to determine the nature and value of $\mathrm{E}_{\mathrm{g}}$ of the NiO NPs.

\section{Conclusions}

In this study, ultrafine NiO NPs were well synthesized under low temperature, $30{ }^{\circ} \mathrm{C}$, by using a simple wet chemical method with an eco-friendly $\mathrm{Ni}(\mathrm{Ac})_{2}$ solution. $\mathrm{NiO}$ NPs were well crystallized with hexagonal structures having $<200>$ preferred orientation even at the lowest temperature. In addition, spherical NiO NPs were well formed with SSA and particle size of $60.14 \mathrm{~m}^{2} / \mathrm{g}$ and ca. 5-15 nm. FT-IR spectra of the NiO NPs showed a sharp vibrating absorption peak only at around $550 \mathrm{~cm}^{-1}$ owing to the Ni$\mathrm{O}$ bond. UV-vis absorption spectra revealed that NiO NPs have the wavelength for absorption edge and their energy band gap is $290 \mathrm{~nm}$ and $3.44 \mathrm{eV}$, respectively. It is expected that the application of this eco-friendly method will contribute to the improvement of manufacturing environment and carbon neutrality.

Author Contributions: Writing—original draft preparation, investigation, S.-J.H.; conceptualization, writing-review and editing, validation, S.-J.H. and Y.-S.K.; software, H.-J.M.; project administration, S.-J.H. and Y.-S.K.; data curation, H.-J.M. and B.-J.K.; supervision, S.-J.H. and Y.-S.K. All authors have read and agreed to the published version of the manuscript. 
Funding: This study was supported by a Korea Institute of Energy Technology Evaluation and Planning (KETEP) grant funded by the Ministry of Trade, Industry and Energy (No. 20205210100070).

Institutional Review Board Statement: Not applicable.

Informed Consent Statement: Not applicable.

Data Availability Statement: Data are available upon request from the corresponding author.

Acknowledgments: This study was supported by Korea Institute of Energy Technology Evaluation and Planning (KETEP) grant funded by the Ministry of Trade, Industry and Energy (No. 20205210100070).

Conflicts of Interest: The authors declare no conflict of interest.

\section{References}

1. Anand, G.T.; Nithiyavathi, R.; Ramesh, R.; Sundaram, S.J.; Kaviyarasu, K. Structural and optical properties of nickel oxide nanoparticles: Investigation of antimicrobial applications. Surf. Interfaces 2020, 18, 100460. [CrossRef]

2. IyyappaRajan, P.; Vijaya, J.J.; Jesudoss, S.K.; Kaviyarasu, K.; Kennedy, L.J.; Jothiramalingam, R.; Al-Lohedan, H.A.; VaaliMohammed, M.A. Green fuel-mediated synthesis of self-assembled NiO nano-sticks for dual applications-photocatalytic activity on Rose Bengal dye and antimicrobial action on bacterial strains. Mater. Res. Express 2017, 4, 085030.

3. Ezhilarasi, A.A.; Vijaya, J.J.; Kennedy, L.J.; Kaviyarasu, K. Green mediated nio nanorods using phoenix dactylifera (Dates) extract for biomedical and environmental applications. Mater. Chem. Phys. 2020, 241, 122419. [CrossRef]

4. Fardood, S.T.; Ramazani, A.; Moradi, S. A novel green synthesis of Nickel oxide nanoparticles using arabic gum. Chem. J. Mold. 2017, 12, 115-118. [CrossRef]

5. Ezhilarasi, A.A.; Vijay, J.J.; Kaviyarasu, K.; Maaza, M.; Ayeshamariam, A.; Kennedy, L.J. Green synthesis of NiO nanoparticles using Moringa oleifera extract and their biomedical applications: Cytotoxicity effect of nanoparticles against HT-29 cancer. J. Photochem. Photobiol. B 2016, 164, 352-360. [CrossRef] [PubMed]

6. El-Kemary, M.; Nagy, N.; El-Mehasseb, I. Nickel oxide nanoparticles: Synthesis and spectral studies of interactions with glucose. Mater. Sci. Semicond. Process. 2013, 16, 1747-1752. [CrossRef]

7. Musevi, S.J.; Aslani, A.; Motahari, H.; Salimi, H. Offer a novel method for size appraise of NiO nanoparticles by PL analysis: Synthesis by sonochemical method. J. Saudi Chem. Soc. 2016, 20, 245-252. [CrossRef]

8. Mohamed, S.; Alsaihi, S. Microwave-assisted synthesis of Nickel oxide nanoparticles using Coriandrum Sativum leaf extract and their structural-magnetic catalytic properties. Materials 2017, 10, 460.

9. Sood, S.; Umar, A.; Mehta, S.K.; Kansal, S.K. Highly effective Fe-doped $\mathrm{TiO}_{2}$ nanorods photocatalysts for visible-light driven photocatalytic degradation of toxic organic compounds. J. Colloid. Interface Sci. 2015, 450, 213-223. [CrossRef]

10. Amanulla, A.M.; Shahina, S.K.J.; Sundaram, R.; Magdalane, C.M.; Kaviyarasu, K.; Letsholathebe, D.; Mohamed, S.B.; Kennedy, J.; Maaza, M. Antibacterial, optical and humidity sensor studies of $\beta-\mathrm{CoMoO}_{4}-\mathrm{Co}_{3} \mathrm{O}_{4}$ nanocomposites and its synthesis and characterization. J. Photochem. Photobiol. B 2018, 183, 233-241. [CrossRef] [PubMed]

11. Ling, S.; Nheu, L.; Dai, A.; Guo, Z.; Komesaroff, P. Effects of four medicinal herbs on human vascular endothelial cells in culture. Int. J. Cardiol. 2008, 128, 350-358. [CrossRef]

12. Raja, A.; Ashokkumar, S.; Marthandam, R.P.; Jayachandiran, J.; Khatiwada, C.P.; Kaviyarasu, K.; Raman, R.G.; Swaminathan, M. Ecofriendly preparation of zinc oxide nanoparticles using Tabernaemontana divaricata and its photocatalytic and antimicrobial activity. J. Photochem. Photobiol. B 2018, 181, 53-58. [CrossRef]

13. Wang, D.; Xu, R.; Wang, X.; Li, Y. NiO nanorings and their unexpected catalytic property for CO oxidation. Nanotechnology 2006, 17, 979-983. [CrossRef] [PubMed]

14. Shigeno, E.; Shimizu, K.; Seki, S.; Ogawa, M.; Shida, A.; Ide, M.; Sawada, Y. Formation of indium-tin-oxide films by dip coating process using indium dipropionate monohydroxide. Thin Solid Films 2002, 411, 56-59. [CrossRef]

15. Rabiei, M.; Palevicius, A.; Monshi, A.; Nasiri, S.; Vilkauskas, A.; Janusas, G. Comparing methods for calculating nano crystal size of natural hydroxyapatite using X-ray diffraction. Nanomaterials 2020, 10, 1627. [CrossRef] [PubMed]

16. Thi Ngo, Y.-L.; Hur, S.H. Low-temperature $\mathrm{NO}_{2}$ gas sensor fabricated with $\mathrm{NiO}$ and renuced graphene oxide hybrid structure. Mater. Res. Bull. 2016, 84, 168-176.

17. Yousaf, S.; Zulfiqar, S.; Shahi, M.N.; Warsia, M.F.; Al-Khalli, N.F.; Aboud, M.F.A.; Shakir, I. Tuning the structural, optical and electrical properties of $\mathrm{NiO}$ nanoparticles prepared by wet chemical route. Ceram. Int. 2020, 46, 3750-3758. [CrossRef]

18. Saion, E.; Gharibshahi, E.; Naghavi, K. Size-controlled and optical properties of monodispersed silver nanoparticles synthesized by the radiolytic reduction method. Int. J. Mol. Sci. 2013, 14, 7880-7896. [CrossRef]

19. Tauc, J. Optical properties and electronic structure of amorphous Ge and Si. Mater. Res. Bull. 1968, 3, 37-46. [CrossRef]

20. Mendelev, M.I.; Srolovitz, D.J. Impurity effects on grain boundary migration. Model. Simul. Mat. Sci. Eng. 2002, 10, R79-R109. [CrossRef]

21. Anandan, K.; Rajendran, V. Morphological and size effects of NiO nanoparticles via solvothermal process and their optical propertie. Mater. Sci. Semicond. Process. 2011, 14, 43-47. [CrossRef]

22. Suresh, S.; Podder, J. Investigations on structural, optical, morphological and electrical properties of nickel oxide nanoparticles. Int. J. Nanoparticles 2015, 8, 289-301. 